\title{
YANGTZE MICROMOLLUSCAN FAUNA AND ITS SIGNIFICANCE
}

YU WEN, Department of Earth and Planetary Sciences, Western Australian Museum, Francis Street, Perth, Western Australia 6000

The Yangtze micromolluscan fauna occurred early in the Cambrian explosion. As such it represents the first biomineralisation event in the evolutionary history of invertebrates and also reflects the first stage of the diversification of the Phylum Mollusca. The fauna occurs in the Lower Cambrian Meishucun Stage of the Yangtze Region of China and includes the Classes Polyplacophora, Merismoconchia, Bivalvia, Monoplacophora, Rostroconchia, Stenothecoida and Gastropoda.

Comparative remarks are presented concerning the genera Yunnanopleura Yu, 1987, Tchangsichiton Yu, 1987, Sinuconus Yu, 1979, Postestephaconus Jiang, 1980, Stoliconus Jiang, 1980, Meishucunchiton Yu, 1987, Runnegarochiton Yu, 1987, Yangtzechiton Yu, 1984, Luyanhaochiton Yu, 1984, Gotlandochiton Bergenhayn, 1955 and Paracarinachites Qian and Jiang, 1982. These are all considered to be Polyplacophora except for Paracarinachites, where affinities are unknown. In Yangtzemerisma rarum $\mathrm{Yu}$ an Unusual microstructure has been observed on a phosphatic internal mould. Yangtzedonta primitiva Yu should be unquestionably assigned to the Class Bivalvia. Monoplacophora are common in the Yangtze micromolluscan fauna. There are six genera preserved with six types of muscle scars on their internal moulds. The genera Archaeospira Yu, 1979 and Yangtzespira Yu, 1979 are similar to each other in general morphology, but this is considered to be due to convergence, likewise the somewhat similar Yangtzechiton and Paracarinachites. In Archaeospira, the aperture is of the holostomatous type, but in Yangtzespira, the aperture is of siphonostomatous type.

It is concluded that the evolutionary tendency of the Phylum Mollusca may be divided into three stages: 1) from shell-less to shell-bearing, 2) from multivalved to univalved and 3) from external to internal shell. 